Jurnal Bidan Cerdas
e-ISSN: 2654-9352 dan p-ISSN: 2715-9965
Volume 3 Nomor 4, 2021, Halaman 176-182
DOI: 10.33860/jbc.v3i4.369

\title{
Hubungan Paritas dengan Kejadian Ruptur Perineum pada Persalinan Normal
}

\begin{tabular}{|c|c|}
\hline open & $\begin{array}{l}\text { ebidanan Poso, Poltekkes Kemenkes Pa } \\
\text { ¿Email: subriah@poltekkes-mks.ac.id }\end{array}$ \\
\hline $\begin{array}{l}\text { ARTICLE INFO } \\
\text { Article History: } \\
\text { Received: } 2021-01-08 \\
\text { Accepted: } 2021-08-27 \\
\text { Published: } 2021-11-30\end{array}$ & $\begin{array}{l}\text { ABSTRAK } \\
\text { Pendahuluan: Meskipun persalinan berjalan secara normal akan tetapi, pada } \\
\text { saat setelah bersalin ibu memiliki berbagai macam risiko komplikasi yang } \\
\text { mungkin terjadi seperti perdarahan karena atonia uteri, retensio plasenta, dan } \\
\text { ruptur perineum. Tujuan: untuk mengetahui hubungan paritas dengan kejadian } \\
\text { ruptur perineum pada persalinan normal. Metode: jenis penelitian ini } \\
\text { menggunakan metode analitik korelasi dengan rancangan potong silang atau } \\
\text { cross sectional. Populasi adalah adalah semua ibu bersalin yang ada di } \\
\text { Puskesmas Kassi Kassi Kota Makassar berjumlah } 30 \text { orang. Teknik } \\
\text { pengambilan sampling menggunakan Consecutive Sampling. Hasil: hasil } \\
\text { penelitian ini menunjukkan } 76,7 \% \text { responden mengalami robekan perineum, } \\
\text { diantaranya } 26,7 \% \text { responden mengalami robekan perineum dejarat } 1 \text { dan } \\
50,0 \% \text { responden mengalami robekan perineum derajat } 2 \text {. Sebanyak } 23,3 \% \\
\text { responden tidak mengalami robekan perineum. Dari hasil uji chi-square dengan } \\
\text { nilai } p=0,05 \text {, hasil probabilitas lebih besar dari taraf signifikan } 5 \% \text { ( } 0,071>0,05) \\
\text { artinya tidak terdapat hubungan paritas dengan robekan perineum pada ibu } \\
\text { dengan persalinan normal di Puskesmas Kassi-kassi Kota Makassar tahun } \\
2020 . \text { Kekuatan hubungan antar variabel agak rendah diperoleh nilai koefisien } \\
\text { Phi }(\mu)=0,488 \text { atau sebesar } 48,8 \% \text {. Kesimpulan: Berdasarkan hasil penelitian } \\
\text { yang telah dilakukan maka dapat disimpulkan tidak ada hubungan paritas } \\
\text { dengan robekan perineum pada persalinan normal. }\end{array}$ \\
\hline
\end{tabular}

Keywords:

Childbirth;

Parity;

Perineal rupture;

ABSTRACT
Introduction: Even though labor was going normally, after giving birth the
mother had various risks of complications that might occur, such as bleeding
due to uterine atony, retained placenta, and perineal ruptur. Objective: to see
the relationship between parity and the incidence of perineal ruptur in normal
delivery. Methods: this type of research uses an analytical method based on a
cross sectional design. The population is all mothers who give birth at the Kassi
Kassi Health Center Makassar City can use 30 people. The sampling technique
used was Consecutive Sampling. Results: The results showed $76.7 \%$ of
respondents experienced perineal tears, of which $26.7 \%$ of respondents
experienced 1 st degree perineal tears and $50.0 \%$ of respondents had grade 2
perineal tears. $23.3 \%$ of respondents did not experience perineal tears. From
the results of the chi-square test with a value of p=0.05, the probability of the
result is greater than a significant tarf of $5 \%(0.071>0.05)$, meaning that there
is no parity relationship with perineal tears in mothers with normal delivery at
the Kassi-Kassi Community Health Center, Makassar City. 2020. The strength
of the relationship between variables is rather low, the value of the Phi
coefficient $(\mu)=0.488$ or $48.8 \%$. Conclusion: Based on the results of the
research that has been done, it can be denied that there is no relationship
between parity and perineal tearing in normal delivery.

(C) 2021 by the authors. Submitted for possible open access publication under the terms and conditions of the Creative Commons Attribution (CC BY SA) license (https://creativecommons.org/licenses/by-sa/4.0/). 


\section{PENDAHULUAN}

Persalinan merupakan suatu proses alamiah yang dialami oleh seorang perempuan. Persalinan merupakan proses mengeluarkan hasil konsepsi baik secara normal maupun secara buatan. Pada pasca persalinan dapat terjadi berbagai macam komplikasi sepertri perdarahan karena atonia uteri, retensio plasenta, dan ruptur perineum (Sigalingging \& Sikumbang, 2018). Ruptur perineum secara global digambarkan dengan prevalensi sebesar $85 \%$ dari seluruh persalinan. Diduga sebesar $0,6-11 \%$ dari seluruh wanita yang melahirkan pervaginam mengalami ruptur perineum derajat 3-4. Insidensi ruptur perineum pada wanita primipara adalah sebesar 90,4\% yang menurun hingga 68,8\% pada wanita multipara (Cola et al., 2016; Goh, Goh, \& Ellepola, 2018)

Pada tahun 2015 angka kejadian robekan perineum yang terjadi di dunia adalah 2,5 juta kasus dan diprediksi akan mengalami kenaikan hingga 50 \% (Pemiliana, Sarumpaet, \& Ziliwu, 2019). Kasus ruptur perineum di Indonesia digambarkan dalam sebuah studi yang dilakukan di Yogyakarta yang mencatat bahwa dari populasi sejumlah 1595 wanita, terdapat 75,3\% ruptur perineum yang terdiagnosis. Ruptur terjadi pada $80,55 \%$ wanita usia muda dan $85,05 \%$ wanita primipara (Pangastuti, 2016). Di Indonesia, prevalensi ibu bersalin yang mengalami ruptur perineum terbanyak dalam rentang usia 32-39 tahun yaitu sebesar 62\% (Kurniawan, Jingsung, Baeda, Anam, \& Siagian, 2020). Hasil penelitian yang dilakukan oleh Puslitbang Bandung adalah sebesar $21,97 \%$ ibu yang bersalin pervaginam mengalami ruptur perineum akan meninggal dunia (Andriani, 2019).

Faktor yang menjadi penyebab terjadinya ruptur perineum diantaranya berasal dari faktor ibu, yaitu paritas, partus presipitatus, persalinan lama dan umur ibu, sedangkan dari faktor janin itu sendiri adalah bayi besar, posisi kepala abnormal, kelahiran bokong dan distosia bahu (Manuaba, 2010). Sementara itu ruptur perineum pada ibu bersalin dapat memberikan dampak seperti terjadinya infeksi luka jahitan yang dimana dapat mengakibatkan munculnya komplikasi infeksi pada kandung kemih maupun pada jalan lahir. Selain itu, ruptur perineum juga dapat mengakibatkan terjadinya perdarahan yang jika penanganan yang diberikan lambat maka akan menyebabkan terjadinya kematian pada ibu.

Berdasarkan hal tersebut upaya yang dapat dilakukan untuk mencegah terjadinya ruptur perineum pada ibu bersalin ialah dengan melakukan pijat perineum. Pijat perineum ini merupakan salah satu cara yang dapat dilakukan untuk meningkatkan kesehatan, aliran darah, elastisitas, dan relaksasi otot-otot dasar panggul, sehingga dapat menurunkan risiko terjadinya ruptur perineum pada ibu. Berdasarkan hasil penelitian yang dilakukan oleh Pemiliana menyatakan bahwa faktor yang berhubungan dengan ruptur perineum pada persalinan normal, yaitu umur, berat badan bayi, dan paritas (Pemiliana et al., 2019). Dari besarnya faktor risiko yang dapat ditimbulkan dari ruptur perineum ini maka peneliti tertarik untuk meneliti mengenai hal tersebut dengan tujuan untuk mengetahui hubungan paritas dengan kejadian Ruptur Perineum di Puskesmas Kassi Kassi Kota Makassar.

\section{METODE PENELITIAN}

Jenis penelitian ini menggunakan metode analitik korelasi dengan rancangan potong silang atau cross sectional. Penelitian ini dilakukan pada bulan Maret hingga Agustus 2020 di Puskesmas Kassi-Kassi Kota Makassar. Populasi dalam penelitian ini adalah semua ibu bersalin yang ada di Puskesmas Kassi Kassi Kota Makassar dalam setahun terakhir sebanyak 218 ibu bersalin. Sampel dalam penelitian ini adalah 
sebagian ibu bersalin di Puskesmas Kassi Kassi Kota Makassar. Besar sampel yang didapatkan dengan menggunakan rumus Lameshow adalah 30 orang. Variabel yang diteliti dalam penelitian ini ialah ruptur perineum dan paritas ibu.

Teknik pengambilan sampel menggunakan teknik Consecutive Sampling yaitu pengambilan sampel yang sesuai kriteria yaitu normal apabila terjadi robekan pada perineum yang meliputi selaput mukosa, kulit dan otot perineum, sedangkan lama apabila terjadi robekan pada perineum yang meliputi selaput mukosa, kulit dan otot perineum sampai kurun waktu tertentu, dengan kriteria inklusi yaitu ibu yang melahirkan secara spontan pervaginam dan bersedia menjadi responden dan kriteria eksklusi yaitu ibu yang melahirkan dengan persalinan buatan dan tidak bersedia menjadi responden.

Adapun teknik pengumpulan data menggunakan data primer berupa lembar observasi. Pengolahan data menggunakan teknik editing, coding, entry, cleaning data entry, tabulating. Analisis data yang dilakukan adalah analisis secara univariat dan bivariat menggunakan Uji Chi Square. Penyajian data menggunakan tabel yang disertai penjelasan secara narasi.

\section{HASIL PENELITIAN}

Berdasarkan hasil penelitian maka diperoleh hasil sebagai berikut:

Tabel 1. Distribusi responden berdasarkan usia, status paritas, dan derajat ruptur

\begin{tabular}{lcc}
\hline \multicolumn{1}{c}{ Karakteristik } & Jumlah $(\mathbf{n = 3 0 )}$ & Persentase (\%) \\
\hline Usia & & \\
$\quad<21$ Tahun & 6 & 20.0 \\
21-35 tahun & 22 & 73.3 \\
$\quad>35$ tahun & 2 & 6.7 \\
Status Paritas & & \\
$\quad$ Primipara & 9 & 30.0 \\
$\quad$ Multipara & 19 & 63.3 \\
$\quad$ Grandemultipara & 2 & 6.7 \\
\hline Derajat Ruptur & & \\
$\quad$ Tidak Ruptur & 7 & 23.3 \\
$\quad$ Derajat 1 & 8 & 26.7 \\
$\quad$ Derajat 2 & 15 & 50.0 \\
\hline
\end{tabular}

Sumber: Data Primer, 2020

Tabel 1 menunjukkan distribusi responden berdasarkan umur. Persentase tertinggi berada pada kelompok umur 20-35 tahun yaitu sebanyak 22 orang $(73,3 \%)$, golongan usia $<21$ Tahun sebanyak 6 orang $(20 \%)$, dan persentase terendah berada pada kelompok usia $>35$ tahun yaitu sebanyak 2 orang $(6,7 \%)$. Untuk karakteristik Paritas ibu menunjukkan distribusi responden berdasarkan status paritas ibu dengan persentase tertinggi berada pada ibu Multipara yaitu sebanyak 19 orang $(63,3 \%)$ sedangkan persentase terendah pada ibu Grandemultipara yaitu hanya 2 orang $(6,7 \%)$.

Sedangkan berdasarkan karakteristik derajat ruptur menunjukkan distribusi responden berdasarkan derajat ruptur perineum dengan persentase tertinggi berada pada ruptur perineum derajat 2 yaitu sebanyak 15 orang $(50,0 \%)$ sedangkan persentase terendah pada tidak mengalami ruptur perineum yaitu hanya 7 orang $(23,3 \%)$. 
Tabel 2 Distribusi Responden berdasarkan Paritas dengan kejadian Ruptur Perineum

\begin{tabular}{|c|c|c|c|c|c|c|c|}
\hline \multirow{3}{*}{ Paritas } & \multicolumn{4}{|c|}{ Kejadian } & \multirow{2}{*}{\multicolumn{2}{|c|}{ Jumlah }} & \multirow{3}{*}{$\begin{array}{c}P- \\
\text { Value }\end{array}$} \\
\hline & \multicolumn{2}{|c|}{ Terjadi } & \multicolumn{2}{|c|}{ Tidak Terjadi } & & & \\
\hline & $f$ & $\%$ & $f$ & $\%$ & $f$ & $\%$ & \\
\hline Primipara & 9 & 30,0 & 0 & 0,0 & 9 & 30,0 & \\
\hline Multipara & 12 & 40,0 & 7 & 23.3 & 19 & 63.3 & \\
\hline Grandemultipara & 2 & 6.7 & 0 & 0,0 & 2 & 6.7 & 0.071 \\
\hline Total & 23 & 76,7 & 7 & 23,3 & 30 & 100,0 & \\
\hline
\end{tabular}

Sumber; Data Primer, 2020

Berdasarkan tabel hasil penelitian tentang hubungan paritas dengan kejadain robekan perineum persalinan normal di Puskesmas Kassi-kassi Kota Makassar, dari 30 responden yang melahirkan secara normal sebanyak 23 responden $(76,7 \%)$ mengalami robekan perineum, diantaranya 8 responden $(26,7 \%)$ mengalami robekan perineum dejarat 1 dan 15 responden $(50,0 \%)$ mengalami robekan perineum derajat 2. Sebanyak 7 responden responden $(23,3 \%)$ tidak mengalami robekan perineum.

\section{PEMBAHASAN}

Dari hasil uji chi-square dengan nilai $p=0,05$, hasil probabilitas lebih besar dari tarf signifikan $5 \%(0,071>0,05)$ artinya tidak terdapat hubungan paritas dengan robekan perineum pada ibu dengan persalinan normal di Puskesmas Kassi-kassi Kota Makassar tahun 2020. Kekuatan hubungan antar variabel agak rendah diperoleh nilai koefisien Phi $(\mu)=0,488$ atau sebesar $48,8 \%$. Sejalan dengan hasil penelitian yang dilakukan oleh Betty dan Febrianti (2015) di Klinik Pratama Widuri Sleman Yogyakarta yang menyatakan tidak ada hubungan paritas ibu bersalin dengan kejadian ruptur perineum dengan $p$-value $>0,05$. Dari 336 sampel sebanyak $75 \%$ mengalami ruptur spontan, paling banyak sampel adalah multipara sebanyak $56,5 \%$. Paritas multipara sebanyak 143 orang 75,3\% mengalami ruptur perineum spontan (Betty \& Febriati, 2018). Penelitian serupa dilakukan oleh Syamsiah (2018), yang menunjukkan tidak terdapat hubungan antara paritas dengan kejadian ruptur perineum dengan nilai $p=0,076$. Sampel penelitian sejumlah 30 orang dengan hasil persalinan didominasi oleh ibu dengan multipara sebanyak 19 (63.3\%) orang yang diantaranya mengalami ruptur perineum adalah 12 orang $(40.0 \%)$ dan 7 orang $(23.3 \%)$ tidak mengalami ruptur perineum, persalinan primipara yang mengalami ruptur perineum adalah 9 orang $(30.0 \%)$, sedangkan persalinan grandemultipara sebanyak 1 orang $(6.7 \%)$ yang mengalami ruptur perineum (Syamsiah \& Malinda, 2019).

Hasil penelitian ini sejalan dengan hasil penelitian yang dilakukan oleh Betty dan Febrianti (2018) di Yogyakarta menunjukkan tidak ada hubungan antara paritas dengan kejadian ruptur perineum. Hal tersebut dikarenakan terdapat faktor lain yang berhubungan dengan terjadinya ruptur perineum yaitu faktor dari ibu ada partus presipitarus, ibu pada saat proses persalinannya tidak mampu berhenti mengejan, sehingga diselesaikan dengan cara tergesa-gesa dengan dorongan fundus yang berlebihan, edema dan kerapuhan pada perineum, varikositas vulva yang melemahkan jaringan perineum. Sedangkan dari faktor dari janin yaitu bayi besar, posisi letak bokong, posisi kepala yang abnormal, dilakukannya ekstraksi forcep, distosia bahu, anomaly kongenital seperti hidrocepalus (Betty \& Febriati, 2018).

Peneliti berasumsi paritas tidak menjadi penyebab utama terjadinya robekan perineum pada ibu bersalin normal. Beberapa faktor dapat menjadi penyebab terjadinya robekan perineum pada ibu bersalin. Penelitian ini tidak sejalan dengan 
hasil penelitian oleh Sigalingging dan Sikumbang (2018) di RSU Imelda Pekerja Indonesia Medan yang mengatakan ada hubungan antara paritas dengan ruptur perineum yang diketahui berdasarkan hasil uji chi square diperoleh nilai $p=0,022$ (Sigalingging \& Sikumbang, 2018).

Penelitian yang lain juga menunjukkan bahwa ada hubungan yang bermakna antara paritas dengan kejadian ruptur perineum pada ibu bersalin secara pervaginam (Hajrah, Purbowati, \& Nuraini, 2019; Pangastuti, 2016; Sari, Supriyatinigsih, \& Sumaryani, 2016; Suryani, 2013). Penelitian yang dilakukan di Rumah Bersalin Atiah menunjukkan bahwa ibu primipara mempunyai resiko 9 kali lebih besar untuk terjadi ruptur perineum (Suryani, 2013), sementara penelitian di Cilincing menunjukkan ibu yang primipara mempunyai peluang 17,1 kali lebih besar untuk terjadinya ruptur perineum (Hajrah et al., 2019). Faktor risiko terjadinya robekan perineum dalam beberapa teori antara lain umur ibu yang terlalu muda atau terlalu tua, dan pertama kali melahirkan (Chigbu, Onwere, Aluka, Kamanu, \& Adibe, 2008; Oxorn, 2010; Pangastuti, 2016). Adapun faktor risiko lain dari ibu juga adalah perineum pendek (kurang dari $3 \mathrm{~cm}$ ), serta adanya riwayat robekan perineum pada persalinan terdahulu.

Dari banyaknya faktor risiko, ibu primipara yang bersalin memiliki risiko lebih tinggi daripada ibu multipara untuk terjadinya ruptur perineum, dilihat lagi dengan keadaan pada saat proses persalinan oleh penolong persalinannya dan dilakukannya asuhan sayang ibu seperti melakukan pijat perineum sebagai tindakan pencegahan terjadinya ruptur perineum (Edqvist, Hildingsson, Mollberg, Lundgren, \& Lindgren, 2017; Hajrah et al., 2019; Oliveira, Brito, Quintana, Duarte, \& Marcolin, 2014; Savitri, Ermawati, \& Yusefni, 2015). Dengan melakukan senam hamil secara rutin yang diawasi oleh tenaga kesehatan yang terampil dapat juga mencegah terjadinya ruptur perenium (Claudia \& Adam, 2018; Kurniawan et al., 2020).

\section{SIMPULAN DAN SARAN}

Berdasarkan penelitian yang dilakukan menunjukkan tidak ada hubungan paritas dengan robekan perineum pada persalinan normal di Puskesmas Kassi-Kassi Kota Makassar. Peneliti mengharapkan bagi ibu hamil terutama multipara hendaknya melakukan senam ibu hamil pada trimester III agar mempunyai perineum yang elastis untuk mengurangi risiko terjadinya ruptur perineum spontan dan menghindari stress dan kelelahan menjelang persalinan untuk mencegah terjadinya partus lama atau partus macet, bagi tenaga kesehatan mengharapkan meningkatkan penyuluhan terhadap ibu hamil tentang factor-faktro yang mempengaruhi robekan perineum sehingga pada saat persalinan kejadian robekan perineum dapat dikurangi dan tingkat robekan perineum dapat diminimalkan, lebih meningkatkan kewaspadaan dalam melakukan pertolongan persalinan sehingga tidak terjadi robekan perineum serta diharapkan mampu memberikan KIE kepada ibu hamil mengenai pengaturan jarak kehamilan.

\section{UCAPAN TERIMA KASIH}

Peneliti menyampaikan terima kasih kepada pihak yang telah berkontribusi dan memberikan dukungan untuk terlaksananya kegiatan penelitian ini, antara lain Poltekkes Kemenkes Makassar, Kepala Puskesmas, bidan di Puskesmas Kassi-Kassi kota Makassar yang telah memberikan bimbingan dan arahan kepada kami sehingga kami dapat menyelesaikan penelitian kami. 


\section{DAFTAR PUSTAKA}

Andriani, Y. (2019). Hubungan Paritas dan Umur lbu dengan Kejadian Ruptur Perineum pada Ibu Bersalin Spontan di Puskesmas Tegalrejo Yogyakarta (Universitas 'Aisyiyah Yogyakarta). Universitas 'Aisyiyah Yogyakarta. Retrieved from http://digilib.unisayogya.ac.id/4477/

Betty, M. K., \& Febriati, L. D. (2018). Hubungan Paritas Ibu Bersalin dengan Kejadian Ruptur Perineum di Klinik Pratama Widuri Sleman Yogyakarta. The Shine Cahaya Dunia S1 Keperawatan, 3(1), 44-49. Retrieved from https://ejournal.annurpurwodadi.ac.id/index.php/TSCS1Kep/article/view/89

Chigbu, B., Onwere, S., Aluka, C., Kamanu, C., \& Adibe, E. (2008). Factors Influencing The Use Of Episiotomy During Vaginal Delivery In South Eastern Nigeria. East African Medical Journal, 85(5). https://doi.org/10.4314/eamj.v85i5.9618

Claudia, J. G., \& Adam, W. S. (2018). Efektifitas Senam Hamil terhadap Kejadian Rupture Perineum pada Ibu Bersalin di Puskesmas Limboto. Gorontalo Journal of Public Health, 1(1), 53-58. Retrieved from https://jurnal.unigo.ac.id/index.php/gjph/article/view/152

Cola, A., Frigerio, M., Manodoro, S., Verri, D., Interdonato, M. L., Nicoli, E., ... Milani, R. (2016). Third and fourth degree perineal tears: incidence and risk factors in an Italian setting. European Journal of Obstetrics \& Gynecology and Reproductive Biology, 206, e27. https://doi.org/10.1016/j.ejogrb.2016.07.095

Edqvist, M., Hildingsson, I., Mollberg, M., Lundgren, I., \& Lindgren, H. (2017). Midwives' Management during the Second Stage of Labor in Relation to Second-Degree Tears-An Experimental Study. Birth, 44(1), 86-94. https://doi.org/10.1111/birt.12267

Goh, R., Goh, D., \& Ellepola, H. (2018). Perineal tears - A review. Australian Journal of General Practice, 47(1-2), 35-38. https://doi.org/10.31128/AFP-09-17-4333

Hajrah, W. O., Purbowati, N., \& Nuraini, N. (2019). Hubungan Faktor Maternal terhadap Posisi pada Waktu Persalinan Kala II dengan Kejadian Ruptur Perineum. Jurnal Bidan Cerdas, 2(1), 31-36. https://doi.org/10.33860/jbc.v2i1.80

Kurniawan, F., Jingsung, J., Baeda, A. G., Anam, A., \& Siagian, H. J. (2020). The Risk Factor of Pregnant Gymnam on The Incidence of Ruptur Perineum in Aliyah Hospital Kendari. Jurnal Kebidanan, 10(2), 138-142. https://doi.org/10.31983/jkb.v10i2.6326

Manuaba, I. B. G. (2010). IImu Kebidanan, Kandungan, dan KB. Jakarta: EGC.

Oliveira, L. S., Brito, L. G. O., Quintana, S. M., Duarte, G., \& Marcolin, A. C. (2014). Perineal Trauma After Vaginal Delivery in Healthy Pregnant Women. Sao Paulo Medical Journal, 132(4), 231-238. https://doi.org/10.1590/1516-3180.2014.1324710

Oxorn, W. (2010). IImu Kebidanan Patologi dan Fisiologi Kebidanan. Yogyakarta: CV Andi Offset.

Pangastuti, N. (2016). Robekan Perineum pada Persalinan Vaginal di Bidan Praktik Swasta (BPS) Daerah Istimewa Yogyakarta Indonesia Tahun 2014-2016. Jurnal Kesehatan Reproduksi, 3(3), 179. https://doi.org/10.22146/jkr.36184

Pemiliana, P. D., Sarumpaet, I. H., \& Ziliwu, S. (2019). Faktor - Faktor Yang Berhubungan Dengan Ruptur Perineum Pada Persalinan Normal di Klinik Niar Medan. Jurnal Kesehatan, 2(2), 170-182. Retrieved from http://jurnal.fkmumi.ac.id/index.php/woh/article/view/woh2209

Sari, A. S., Supriyatinigsih, S., \& Sumaryani, S. (2016). Hubungan antara Paritas dengan Kejadian Rupture Perineum pada Persalinan Normal di Klinik Utama Asri Medical Center Yogyakarta dan RSUD Panembahan Senopati Bantul. Jurnal Kesehatan Reproduksi, 2(3), 190-196. https://doi.org/10.22146/jkr.12657

Savitri, W., Ermawati, E., \& Yusefni, E. (2015). Pengaruh Pemijatan Perineum pada Primigravida terhadap Kejadian Ruptur Perineum saat Persalinan di Bidan Praktek Mandiri di Kota Bengkulu Tahun 2014. Jurnal Kesehatan Andalas, 4(1). https://doi.org/10.25077/jka.v4i1.204

Sigalingging, M., \& Sikumbang, S. R. (2018). Faktor yang Berhubungan dengan Terjadinya Rupture Perineum pada Ibu Bersalin di RSU Imelda Pekerja Indonesia Medan. Jurnal Bidan Komunitas, 1(3), 161-171. https://doi.org/10.33085/jbk.v1i3.3984 
Suryani. (2013). Faktor-Faktor yang Berhubungan dengan Ruptur Perineum pada Persalinan Normal di Rumah Bersalin Atiah. Jurnal Kesehatan, 4(1), 277-283. Retrieved from https://ejurnal.poltekkes-tjk.ac.id/index.php/JK/article/view/12

Syamsiah, S., \& Malinda, R. (2019). Determinan Kejadian Ruptur Perineum di BPM E.N Surabaya. Jurnal IImiah Kesehatan, 10(2), 190-198. https://doi.org/10.37012/jik.v10i2.54 